\title{
PRESENTACIÓN \\ Discurso, epistemologías del Sur y pedagogías decoloniales
}

Luciana Maria Almeida de Freitas ${ }^{a}$ (D)

Maria Paula Meneses ${ }^{b}$ (D)

\footnotetext{
${ }^{1}$ El Sur Global, como metáfora, se refiere al espacio geopolítico marcado por la opresión generada por el capitalismo, el colonialismo y el patriarcado. En este sentido, el Sur Global es una constelación de aspiraciones políticas, ontológicas y epistemológicas, cuyo saberes los valida el éxito de las luchas.
}

Septiembre de 2021. Una tragedia sanitaria, con innumerables consecuencias en otros campos, afecta al mundo desde hace dieciocho meses. Ya tan desigual, el mundo está aún más marcado por el desequilibrio, con un Norte Global, en general, mostrando signos de una posible recuperación y un Sur Global, especialmente Brasil, todavía enfrentando muchos problemas ${ }^{1}$. Sin embargo, el Covid-19 no solo reforzó la desigualdad geopolítica. Por un lado, según una famosa lista de multimillonarios organizada por un vehículo de prensa internacional, la pandemia enriqueció aún más a los representantes del gran capital. Solo en América Latina y Caribe, hubo un aumento del $40 \%$ en el número de multimillonarios. Por otro lado, la crisis del Covid-19 ha aumentado significativamente el hambre en el mundo, como lo indica la Organización de las Naciones Unidas para la Alimentación y la Agricultura (FAO; FIDA; UNICEF; PMA; OMS, 2020)

La educación, en todos sus niveles, modalidades y etapas, no podría dejar de verse afectada -mucho- por la situación mundial, en sus aspectos sanitarios, económicos y sociales. Si bien este número 56 de la Revista Gragoatá no aborda los efectos de la pandemia en la educación y la formación docente, sus ecos están presentes, explícita o

\footnotetext{
aUniversidade Federal Fluminense, Faculdade de Educação, Programa de Pós-Graduação em Estudos de Linguagem. Niterói, RJ, Brasil. E-mail: lucianafreitas@id.uff.br

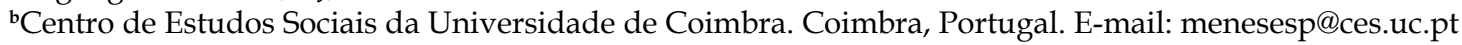

Como citar:

FREITAS, L.M.A.; MENESES, M.P. Discurso, epistemologías del Sur y pedagogías decoloniales. 
implícitamente, en la publicación. Como prácticas lingüísticas que son, los textos de este dossier son signos ideológicos que, por un lado, integran el mundo social y, por otro, reflejan y refractan la existencia, como ya advertía, en 1929, Volóchinov (2017).

La recopilación de artículos derivados de investigaciones sobre educación lingüística y formación docente en el Sur Global es de indudable relevancia, ya sea en el trágico contexto de los últimos meses o en otros momentos históricos. Después de todo, las desigualdades entre el Norte y el Sur Global se reflejan en la educación, que puede reproducirlas y reforzarlas o cuestionarlas; en palabras de Paulo Freire (1987), Patrono de la Educación Brasileña y referencia mundial en el campo educativo, puede ser una educación bancaria o liberadora. Por tanto, es una reflexión pertinente y necesaria, más aún al enfocar, como propone este volumen, las Epistemologías del Sur como abordaje pedagógico en la lucha contra la exclusión y el silenciamiento, por la educación hegemónica de matriz eurocéntrica y del Norte Global, de pueblos y culturas colonizadas. Asimismo, el debate cobra importancia con la discusión de perspectivas pedagógicas decoloniales y discursos alternativos sobre la enseñanza, currículo, materiales didácticos, praxis educativa y políticas públicas educativas o sobre discursos educativos de grupos socialmente minorizados, en diferentes dimensiones: clase, raza, etnia, género, orientación sexual y generación.

Por ello, este número de la Revista Gragoatá, que trata sobre "Discurso, Epistemologías del Sur y Pedagogías Decoloniales", busca contribuir con la ampliación del rol pedagógico y transformador de la educación, trabajando por la emancipación de sociedades, culturas y políticas, por sociedades más justas y humanas. En este contexto, es importante denunciar las matrices capitalistas, coloniales y patriarcales que aún marcan los proyectos educativos contemporáneos. Los artículos de este número contribuyen a pensar alternativas, desde el Sur, a los discursos y prácticas dominantes de la educación, en un diálogo basado en numerosas experiencias, prácticas y visiones educativas locales que traen beneficios directos a los grupos subalternos en las Américas, tales como como los pueblos indígenas, movimientos afrodescendientes, movimientos LGBTQIA+, y que fomentan el diálogo con otros contextos. 
La educación es un terreno privilegiado para el desarrollo, transmisión y producción de conocimiento. Dada la interrelación entre la educación y las instituciones educativas, por un lado, y la epistemología y el conocimiento, existe un número creciente de estudios críticos que exponen diversos elementos que reflejan la continuidad del colonialismo moderno en el campo educativo. Por otro lado, y ampliando los desafíos lanzados por Paulo Freire, existe un número creciente de trabajos que buscan promover nuevas prácticas educativas que permitan una transformación radical de las relaciones sociales (FREIRE, 1978).

Los conocimientos tienen identidades distintas, produciendo articulaciones entre sí, producto de las necesidades y objetivos de las luchas sociales. Como subraya Boaventura de Sousa Santos (2019), al proponer las Epistemologías del Sur, es importante reconocer y valorar la diversidad de conocimientos en el mundo, mientras que es urgente construir procedimientos capaces de promover el interconocimiento y la interinteligibilidad. Es un Sur epistémico y no el geográfico, que adquiere diversas expresiones en los múltiples lugares del mundo donde se desarrollan las experiencias de lucha, incluidas las educativas.

Pensar desde el Sur pasa por una descolonización epistémica del universo de las experiencias humanas, basada, por un lado, en la categorización del otro y de sus saberes como local o inferior y, por otro, en la legitimación como único saber válido de una forma de conocimiento: la ciencia. Para que esto sea posible, es ineludible el concepto propuesto por Santos de pensamiento abisal para caracterizar el pensamiento que, en nuestro tiempo, permanece rehén de las formas coloniales de interpretar el mundo. El pensamiento abisal se constituye

${ }^{2}$ Original: um "sistema de distinções visíveis e invisíveis, sendo que as invisíveis fundamentam as visíveis. As distinções invisíveis são estabelecidas através de linhas radicais que dividem a realidade social em dois universos distintos: o universo 'deste lado da linha', da metrópole, e o universo 'do outro lado da linha'"'. a partir de un "sistema de distinciones visibles e invisibles, donde lo invisible sustancia las visibles. Las distinciones invisibles se establecen a través de líneas radicales que dividen la realidad social en dos universos distintos: el universo 'de este lado de la línea', de la metrópoli, y el universo 'del otro lado de la línea'" (SANTOS, 2007, p. 3, traducción nuestra²), del espacio colonizado. Esta división abisal producida por la epistemología imperial hace que "el otro lado de la línea" sea insignificante, residual como realidad, o incluso se produzca como inexistente. Este pensamiento abisal, fundacional de la 
modernidad, construye a los sujetos del Sur como objetos de los que se habla y que no reconocen como plenamente humanos. En todo caso, son seres sin saberes útiles para los centros metropolitanos coloniales (SANTOS, 2007).

En una época como la nuestra, marcada por crecientes disparidades económicas y educativas, crisis ambientales, violación permanente de los derechos humanos, guerras y episodios de violencia armada, degradación de la democracia y crisis financieras, ¿cómo puede la educación contribuir a anticipar otro mundo posible? En el centro de esta reflexión es la identificación de ausencias y emergencias (SANTOS, 2002). Si la tarea de la sociología de las ausencias es producir un diagnóstico radical de las relaciones sociales latentes capitalistas, coloniales y patriarcales, la sociología de las emergencias, a su vez, busca transformar el paisaje generado por el diagnóstico de ausencia en un vasto campo de experiencia social viva, rica e innovadora. Estas dos condiciones son fundamentales para las Epistemologías del Sur, ya que la justicia social no es posible sin la justicia cognitiva (MENESES, 2009). Nilma Lino Gomes (2017, p. 41) desarrolla estos desafíos y propone una "pedagogía de ausencias y emergencias" que, por un lado, potencia el reconocimiento de la producción de no existencia de ciertos saberes en el ámbito escolar -por ejemplo, los saberes de grupos no hegemónicos y contrahegemónicos- y, por otro lado, la no conformidad con estas brechas y las expectativas de que serán superadas a través de procesos concretos que permitan la integración concreta de nuevos saberes (GOMES, 2017). La posibilidad de ampliar la presencia de otras pedagogías en las escuelas actuales requiere un análisis contextual de las consecuencias del colonialismo ultramarino europeo en las expresiones sociales, políticas y culturales contemporáneas. Sin embargo, como las especificidades de cada contexto colonial fueron diferentes (LOOMBA, 2002), también lo son las opciones para una educación emancipadora, basada en semillas de emergencias. Como destacan los artículos de este número de la revista, hay una idea clave: es urgente descolonizar la educación.

Esta lucha por la descolonización es uno de los elementos fundamentales del siglo XX y continúa en la actualidad. La descolonización incluye analizar luchas, compromisos, acuerdos y resultados, repensar los aspectos fundamentales de 
quién tiene el poder y quién lo disputa. Como destacó Franz Fanon (2005), el horizonte final de la descolonización representa la construcción de una nueva humanidad capaz de escapar a la lógica de la repetición interminable de la destrucción de saberes en los espacios coloniales. A su vez, para Nkrumah (1965), la descolonización es la creación de una humanidad política y económicamente autónoma. Para Gandhi (1956) y Sukarno (1955), la descolonización es la posibilidad de decidir el presente y el futuro a partir de las condiciones, posibilidades y conocimientos existentes.

Los desafíos a la descolonización de las mentalidades (ALATAS, 1974; THIONG'O, 1993) han tomado diferentes formas, marcadas por la especificidad de la intersección de las luchas contra el capitalismo, el patriarcado y el colonialismo, en diferentes regiones y en diferentes momentos históricos. Para Santos (2019), la descolonización significa la lucha por un mundo post-abisal, un mundo que elimine las exclusiones abisales, aquellas que implican la degradación ontológica y epistémica de los grupos excluidos. La inevitabilidad del proceso de descolonización está asociada a la liberación del "régimen de la verdad" difundido por el proyecto colonial, que incluye, entre otros aspectos, como dice Fanon (2008), la disolución del complejo de inferioridad y alienación de los colonizados, resultado del proyecto político colonial moderno, epítome del Norte Global (MENESES, 2018).

En contraste con el agotamiento intelectual y político del Norte Global, el Sur Global, en su inmensa diversidad, se asume hoy como un vasto campo de innovación social, cultural, política, económica y epistémica, un punto de partida para repensar la diversidad epistémica y pedagógica del mundo. En este sentido, la denuncia del "otro" lado de la línea abisal y la lucha por superarla es el punto de partida de las Epistemologías del Sur y sus propuestas para repensar la diversidad epistémica del mundo. El camino de seleccionar las mejores opciones y prácticas didáctico-pedagógicas que contribuyan a superar la jerarquía de culturas y la línea abisal que marca el colonialismo en el ámbito escolar está lleno de dificultades y problemas. Sean opciones decoloniales, postcoloniales o de las Epistemologías del Sur, el camino no es ni seguro ni lineal, porque está marcado por relaciones y luchas de poder (SILVA, 2001). Este conjunto de opciones críticas al 
${ }^{3}$ Original: "a lógica subjacente da fundação e do desdobramento da civilização ocidental desde o Renascimento até hoje".
${ }^{4}$ Original: "A

colonização falseia as relações humanas, destrói ou esclerosa as instituições e corrompe os homens colonizadores e colonizados. [...] Se o europeu deve aniquilar em si o colonizador, o colonizado deve superar o colonizado". modelo pedagógico actual es un instrumento importante para repensar cómo afrontar las ausencias que marcan los currículos y para identificar conocimientos emergentes que es importante integrar. Como enfatiza Candau (2020), es necesario no solo deconstruir la perspectiva estandarizadora de la escuela y de los currículos escolares para cuestionar su colonialidad, sino también reconocer posibles saberes y prácticas insurgentes de la vida escolar cotidiana, llevados a cabo por docentes, que traen grupos sociales subordinados e inferiorizados al centro del debate.

Los estudios decoloniales surgieron en el contexto latinoamericano a fines del siglo pasado, muy impulsados por las reflexiones de autores como Anibal Quijano (2000). Para los estudios decoloniales críticos, el colonialismo se identifica como "la lógica subyacente de la fundación y desarrollo de la civilización occidental desde el Renacimiento hasta nuestros días" (MIGNOLO, 2017, p. 2, traducción nuestra33). El enfoque decolonial expone las relaciones jerárquicas - raciales, políticas y sociales-impuestas por el colonialismo europeo moderno en Latinoamérica, al tiempo que caracteriza el legado vivo del colonialismo, una articulación del poder racial, de clase y de género, y las estructuras de conocimiento que sobrevivieron al colonialismo histórico y que todavía forman parte de los sistemas pedagógicos del siglo XXI (WALSH, 2009). En el campo educativo, las opciones decoloniales indican la urgencia de cambios sustantivos en el contexto educativo. En el caso brasileño, por ejemplo, una opción decolonial implica una articulación del saber y autoría indígena y afrobrasileña a todo el proyecto escolar, así como una interpretación de la esclavitud basada en historias e informes de resistencia negra.

Los estudios postcoloniales, otra corriente del pensamiento crítico, también afirman que las consecuencias destructivas del colonialismo se expongan, analicen y aborden para que se pueda superarlas. Como destaca Albert Memmi (2007, p. 189, traducción nuestra $\left.{ }^{4}\right)$, "la colonización falsea las relaciones humanas, destruye o esclerosa instituciones y corrompe a los colonizadores y colonizados. [...] Si el europeo debe aniquilar al colonizador en sí mismo, el colonizado debe superar al colonizado". La educación postcolonial aborda la presencia del imperialismo cultural, reconociendo su legado en los currículos escolares y los supuestos occidentales sobre el conocimiento 
y el mundo que lo mantiene, promoviendo una pedagogía de crítica y transformación tanto de la vieja metrópoli como de los nuevos territorios independientes. La globalización en el siglo XXI sigueintensificado las interacciones entre las antiguas metrópolis y sus antiguas colonias, en un sistema global cada vez más integrado en el que las influencias neoliberales han buscado encarnar una nueva forma de imperio que englobe la educación. Uno de los elementos importantes de los estudios postcoloniales es la demanda de (re)introducción de otros saberes y pedagogías en la educación como respuesta a la expropiación cultural (SMITH, 1999). Otras direcciones en el pensamiento educativo postcolonial buscan acomodar los saberes indígena (MUNDURUKU, 2012), la criollización (MARIMOUTOU; VERGÈS, 2005) y cumplir con las condiciones materiales de la desigualdad global (TUCK; YANG, 2012).

Como destaca esta muy breve introducción, las perspectivas analíticas o teóricas que subyacen al pluriverso decolonial y postcolonial revelan superposiciones significativas, y las diferencias a veces son el resultado de tradiciones intelectuales preexistentes (SANTOS, 2019). En un contexto académico marcado por la hostilidad reaccionaria (blanca, racista, patriarcal, capitalista) a este tipo de estudios y desafíos educativos, la complementariedad y el diálogo son urgentes y necesarios para ampliar la descolonización de la educación.

Finalmente, las Epistemologías del Sur se caracterizan por una doble investigación cognitiva basada en la idea de que no hay justicia social global sin justicia cognitiva global. Por un lado, buscan rescatar saberes vernáculos movilizados en luchas que nunca se reconocieron como contribuciones relevantes para una mejor comprensión del mundo por la racionalidad científica moderna. Esta exclusión cognitiva va de la mano de la exclusión social y la destrucción de saberes, lenguas, pueblos y culturas. Por ejemplo, la destrucción de la gran mayoría de los pueblos indígenas de América y sus formas de vida -genocidio- siempre fue la otra cara de la destrucción -la demonización, el olvido- de sus formas de saber -epistemicidio y linguicidio (SANTOS, 2019). Por otro lado, las Epistemologías del Sur revelan cómo las luchas sociales concretas generalmente recurren a varios tipos de conocimiento -popular o vernáculo- que se combinan con el conocimiento científico. Por ejemplo, las luchas contra los 
${ }^{5}$ Original: "concebido como elemento discursivo da política educacional, que os diferentes grupos sociais, especialmente os dominantes, expressam sua visão de mundo, seu projeto social, sua 'verdade"'.

${ }^{6}$ Original: "o direito ao conhecimento, às ciências e tecnologias com o direito às culturas, aos valores, ao universo simbólico, ao corpo e suas linguagens, expressões, ritmos, vivências, emoções, memórias e identidades diversas". agrotóxicos en Brasil combinan saberes campesino con saberes de agronomía, salud pública, bioquímica, ciencias sociales, incluido el análisis de las problemas de propiedad de la tierra (CARNEIRO et al., 2020). Estas articulaciones y combinaciones, ecologías de saberes, transforman mutuamente diferentes formas de saber al entablar diálogos encaminados a fortalecer las luchas sociales contra la dominación, donde la educación juega un papel importante. Funcionando casi como un proyecto que reúne las posibilidades de investigación y activismo que denuncian la violencia en la educación del capitalismo, colonialismo y patriarcado, las Epistemologías del Sur como propuesta intelectual se centran en la lucha como resistencia contra la dominación y la opresión, denunciando las líneas abisales de exclusión y apelando a las emergencias de saberes, incluido el uso de otras lenguas y saberes (SANTOS, 2019).

Es, por medio del currículo, "concebido como elemento discursivo de la política educativa, que diferentes grupos sociales, especialmente los dominantes, expresan su cosmovisión, su proyecto social, su 'verdad' (SILVA, 2001, p. 11, traducción nuestra ${ }^{5}$. El cambio curricular, la alteración de los procesos pedagógicos, los diálogos entre saberes son caminos posibles para descolonizar el currículo, la escuela, abriendo el camino a una educación emancipadora (MENESES, 2016). En este caso, no se trata solo del currículo como documento prescriptivo impuesto por organismos gubernamentales, como es el caso actualmente en Brasil, con fuerte apoyo de fundaciones privadas controladas por el capital internacional, sino como praxis, como lo que realmente sucede en las escuelas, en las aulas, en la interacción entre los profesionales de la educación y los estudiantes.

Pensar la educación en esta perspectiva presupone una ampliación de visión, una extrapolación del enseñar y el aprender. La noción de educación integral, según Arroyo (2012, p. 44, traducción nuestra ${ }^{9}$ ), es productiva para ello. El autor la entiende como un proceso escolar que articula "el derecho al conocimiento, la ciencia y la tecnología con el derecho a las culturas, los valores, el universo simbólico, el cuerpo y sus lenguajes, expresiones, ritmos, vivencias, emociones, recuerdos e identidades diversas". Por lo tanto, se trata de algo que va más allá de "instruir" y supone "formar" (FREIRE, 1996). 
Muy cerca de esta perspectiva integral se encuentran los artículos del número 56 de la Revista Gragoatá. Todos se centran en la educación, ya sea escolar o no, o en la formación docente. Algunos dirigen su mirada a las Pedagogías Decoloniales y otros a las Epistemologías del Sur. La diversidad de objetos o sujetos investigados en los textos del volumen es muy representativa de los temas presentes en las investigaciones sobre la educación en Brasil desde estos dos campos teóricoepistemológicos. Así, existen textos que debaten género, tanto en relación a mujeres como a LGBTQIA+, y cuestiones étnico-raciales, con énfasis en los pueblos originarios, en las comunidades quilombolas y discusiones que involucran a la negritud. Además, los artículos también abordan la educación lingüística y literaria, así como presentan reflexiones sobre temas de relevancia social y cultural, como los derechos humanos, el racismo, la docencia, el discurso amoroso, entre otros. Cabe señalar que todos los autores y autores trabajan en Brasil y la mayoría de los textos abordan el contexto brasileño; sólo dos se vuelven hacia México.

El primer artículo, "De-universalizing the decolonial: between parentheses and falling skies", de Ana Paula Martínez Duboc y Lynn Mario Trindade Menezes de Souza, presenta una relevante discusión teórica crítica sobre la decolonialidad, defendiendo la vuelta del cuerpo y la marcación de lo no marcado para interrumpir la colonialidad. Para iniciar la discusión, la autora y el autor analizan la obra The falling Sky: words of a Yanomami shaman, de Kopenawa y Albert (2013), un relato sobre la historia de vida y el pensamiento del chamán yanomami Davi Kopenawa. El libro se toma como un ejemplo de pedagogía decolonial que pone los conocimientos entre paréntesis, desencadenando una traducción intercultural. Para que el cielo no se caiga, mito recurrente en las culturas indígenas, es necesario mantener vivos los rituales y saberes de las comunidades, siempre amenazadas por la colonialidad.

Luego, los lectores podrán disfrutar de "In my skin: racial education and Post Abyssal Thinking of black aesthetics", de João Paulo Xavier. Llevando la negritud en su propia piel, el investigador presenta reflexiones, maduradas en otros textos, sobre el importante concepto, de su autoría, de "racismo estético". A través de narrativas autobiográficas de afrobrasileños, buscando suscitar reflexiones sobre el racismo 
en los sujetos participantes en la investigación, el texto se centra en la discriminación de los rasgos fenotípicos de negras y negros. Xavier discute, con precisión y sensibilidad, la forma en que la estética blanqueadora afecta los cuerpos negros y las identidades afrodiaspóricas y cómo, en una perspectiva post-abisal y rompiendo con los paradigmas coloniales de producción y apropiación del conocimiento, es relevante la afirmación de modelos estéticos afrocéntricos.

$\mathrm{El}$ artículo "Language education in english as an aditional language in Brazil: overcoming the colonial practices of teaching english as a foreign language", de Ricardo Luiz Teixeira de Almeida, analiza las influencias ideológicas de las prácticas hegemónicas en la enseñanza del inglés impulsadas por la Gran Bretaña y los Estados Unidos en países del Sur Global, con foco en Brasil. Ante tales prácticas coloniales, el texto propone alternativas que podrían descolonizar el aula de inglés. Esto sugiere el cambio, que no es solo terminológico, a una educación lingüística en inglés como lengua adicional. Con una reflexión relevante, construida a lo largo de muchos años de dedicación a la escuela pública, el autor defiende una aproximación a los valores, propósitos y necesidades de los jóvenes de las clases populares, con la adopción de pedagogías participativas, para permitir que los estudiantes brasileños se apropien de la lengua inglesa.

Del debate sobre la educación lingüística en inglés, pasamos, en el siguiente texto, a la lengua española. En "Educação de saias coloridas: aprender espanhol com mulheres da América Latina", Marcia Paraquett presenta un debate sobre género y raza en una propuesta de currículo intercultural para lenguas extranjeras en Brasil. El artículo discute las bases epistemológicas de lo que propone al ponerle faldas a la educación, como afirma Paraquett. Así, utiliza los aportes de mujeres que viven en Latinoamérica, como Catherine Walsh, Ana Pizarro, Nilma Lino Gomes, Ana Lúcia Silva Souza y Silvia Rivera Cusicanqui. Defendiendo la interculturalidad como igualdad y equidad, Paraquett nos muestra, con este artículo, que es otra mujer con faldas de colores que necesita estar presente como gran referente en las reflexiones sobre la educación lingüística en lengua española en Brasil.

Posteriormente, Beatriz dos Santos Feres presenta a las/ os lectoras/es "Análise do discurso amoroso em contos ilustrados: 
uma contribuição para a sociologia das emergências". A partir de dos perspectivas construidas por hombres europeos, el texto presenta su exitosa apropiación y reconstrucción desde el lugar de habla de una mujer latinoamericana. Por tanto, analiza la constitución verbal-visual en el discurso amoroso de dos cuentos ilustrados: Uma princesa nada boba, de Luiz Antonio, ilustrada por Biel Carpenter (2011), y Amoras, de Emicida, ilustrada por Aldo Fabrini (2018). Buscando verificar elementos afirmativos de las luchas de las minorías a través de mecanismos de implicitación de un pensamiento decolonial, el artículo une "corazonadamente" emoción y razón, buscando contribuir a una pedagogía liberadora.

En "Etno-histórias nas escolas brasileiras: um caminho de aproximação com os povos indígenas", Rogério Back, Ana Paula Marques Beato-Canato y Marcel Alvaro de Amorim enfocan la literatura indígena. Con el objetivo de aproximarse a los pueblos originarios de Brasil a través de su literatura, el artículo va más allá de las imposiciones legales sobre la inclusión de la historia y cultura indígena en el currículo de educación básica; la propuesta es trabajar, desde una perspectiva decolonial, los textos literarios como ejercicio exotópico, permitiendo el protagonismo de diferentes pueblos originarios y sus luchas e historias. Al rechazar visiones estereotipadas sobre temas étnico-raciales, el artículo refuerza la importancia de la literatura para la visibilidad de los pueblos indígenas y la necesidad de una redefinición de su lucha y sus imaginarios. Para ejemplificar la propuesta, utilizan el poema Pé no chão, de Gustavo Caboco.

Las cuestiones de género están presentes en este dossier no solo con un enfoque en las mujeres; esto es lo que vemos en "Por uma educação linguística queer: estranhando conceitos e práticas", de Daniel Mazzaro. En una propuesta inédita y audaz, el artículo defiende una subversión del aprender y el enseñar lenguas a través de una educación lingüística críticamente queer. A partir de discusiones sobre género y sexualidad, principalmente de Butler, y de estudios decoloniales, el texto articula nociones de educación lingüística a tales debates, llegando a una práctica que reúne elementos culturalmente extraños y tradicionalmente ausentes en los estudios de lenguaje. La propuesta también avanza hacia el autoextrañamiento para reconstruir el poder, el saber y el ser 
de la alteridad invisible, tanto de sujetos LGBTQIA+ como de otros grupos socialmente minorizados. Su pedagogía queer y "desencajante" saca a la luz temas, saberes y personas hasta ahora silenciadas.

El artículo de André Marques do Nascimento, “Linguagem e arte em contextos interculturais: o potencial epistemológico do rap para a educação linguística de docentes indígenas em formação superior na Universidade Federal de Goiás", se centra en un tema muy relevante: la formación de profesores indígenas de más de veinte etnias en el Grado en Educación Intercultural en la región de Araguaia-Tocantins desde los principios de la interculturalidad crítica y la decolonialidad. La sensible investigación etnográfica reportada por Nascimento presenta una propuesta formativa en educación lingüística que tiene como eje la cultura y el potencial contestatario del rap y del hip-hop. Como manifestaciones ancladas en historias y en cuerpos marginados por la colonialidad, su proximidad a las vivencias de los pueblos indígenas en formación permitió una importante adhesión de estudiantes de grado, desafiando proyectos globales hegemónicos.

Lívia Tiba Rádis Baptista, en "Lócus de enunciação e coletivo mexicano Batallones Femeninos: cartografando uma pedagogia decolonial no Sul Global", analiza este colectivo de mujeres raperas que busca difundir prácticas decoloniales en una producción artística, especialmente musical y escénica, en la Frontera Norte de México. El lugar de origen de Batallones Femeninos nos permite observar las diferentes dimensiones de la tensión generada por la geopolítica del Sur y del Norte Global. Así, analizando el locus de enunciación presente en las prácticas lingüísticas del colectivo, el artículo muestra el lugar que ocupan estas mujeres en el mundo y cómo una praxis pedagógica decolonial permite tal sustancialización. Compartiendo la perspectiva ampliada de Walsh (2009) sobre la pedagogía, el artículo entiende que las luchas sociales son pedagógicas, ya que son espacios de aprendizaje, reflexión y acción.

En esta misma perspectiva pedagógica expandida y enfocando prácticas discursivas producidas en México, Antonio Andrade y Patricia Araujo Fernandes producieron "Cores e pedagogias do discurso zapatista". Centrándose en un texto narrativo literario titulado La historia de los colores, 
escrito por el Subcomandante Marcos como comunicado del Ejército Zapatista de Liberación Nacional, movimiento de resistencia indígena, el artículo tiene como objetivo discutir la inflexión pedagógica decolonial del discurso zapatista. Articulando transdisciplinariamente perspectivas discursivas, pedagogía decolonial y Epistemologías del Sur, Andrade y Fernandes reflexionan sobre el valor crítico y pedagógico de la transposición literaria realizada en La historia de los colores para la deconstrucción de los paradigmas coloniales y la matriz epistemológica eurocéntrica.

Volviendo a la educación formal, más concretamente a la formación docentes, el siguiente artículo, de Fábio José Paz Rosa, se titula "Da janela da minha casa: aprendizagens com pedagogias quilombolas por meio de imagens cinematográficas". Vinculando cine, educación y temas étnico-raciales, el texto presenta una investigación desarrollada en medio de la pandemia Covid-19 en un grado en Pedagogía en la región metropolitana de Río de Janeiro. Centrándose en el cine quilombola negro, la investigación propone pensar la formación del profesorado a través de epistemologías quilombolas, involucrando corporeidad, naturaleza y territorialidad. La experiencia de los futuros profesores con el cine quilombola permitió, a través de la pedagogía decolonial, una reflexión sensible y relevante sobre la formación del profesorado y sobre epistemologías no hegemónicas.

Centrándose en la educación básica y los pueblos originarios, Icléia Caires Moreira y Vânia Maria Lescano Guerra son los autores de "Representações: marcas abissais da In-exclusão em material didático sobre povos indígenas". El tema central del artículo es la representación del sujeto indígena y del sujeto blanco en la labor educativa de los pueblos indígenas en Brasil. En una perspectiva teórica transdisciplinaria, que reúne los estudios discursivos, la Arqueogenealogía de Foucault, la decolonialidad y las elaboraciones del educador indígena Daniel Munduruku, el artículo apunta hacia una docilización de los cuerpos y un refuerzo de la cultura como consumo, según los ideales del Norte Global. La obra didáctica, señala el artículo, es un dispositivo de poder que busca paliar la herida colonial y la exclusión de las poblaciones indígenas, reforzando su condición de subordinación y marginalidad. 
Luego, una vez más, el texto literario pasa a primer plano en "Ensino de literaturas e decolonialidade: por uma educação literária democrática", de Rodrigo Corrêa Martins Machado y Douglas Vinicius Souza Silva. Basado en estudios decoloniales, el artículo analiza la enseñanza de la literatura en Brasil considerando las percepciones de la democracia y los derechos humanos. Para ello, utiliza el clásico "El derecho a la literatura", de Antonio Candido, y avanza en estudios más recientes que permiten comprender la juventud contemporánea. Por lo tanto, Machado y Silva defienden una educación literaria democrática basada en los derechos humanos. Así, según el artículo, la escuela debe presentar a los estudiantes, por un lado, la literatura canónica, dando acceso a dichos bienes culturales; por otro, llevar a debate obras producidas por grupos sociales subalternizados.

También para sacar a la luz el debate sobre los derechos humanos, el siguiente artículo es "Construindo um currículo decolonial com as vozes do sul: inglês como língua de denúncia contra violações de direitos humanos", de Lesliê Vieira Mulico y Patrícia Helena da Silva Costa. El texto presenta una propuesta curricular para la enseñanza del inglés con un enfoque en la "literacidad humana", es decir, en contenidos y actividades que permitan a los defensores de derechos humanos utilizar la lengua como medio de resistencia y denuncia de violaciones, considerando su carácter de lengua hegemónica de la globalización imperialista. El levantamiento de necesidades de los estudiantes se realizó a través de cuestionarios, lo que resultó en un número significativo de respuestas. Así, se elaboró la propuesta curricular, a partir de temas, literacidades, formas-funciones y géneros discursivos.

Abordando un tema único en este dossier, Souzana Mizan y Rodrigo Abrantes da Silva presentan "Práticas decoloniais na plataforma educacional CGScholar: subjetificação, ecologia de saberes e o design de textos rizomáticos multimodais". El artículo narra una experiencia con la asignatura Lengua Inglesa en un grado de formación docente utilizando la plataforma educativa CGScholar, durante la pandemia de Covid-19, cuando la mayoría de las universidades brasileñas optó por el aprendizaje digital a distancia. Articulando prácticas decoloniales de subjetivación, ecología de saberes y escritura rizomática multimodal, el texto reflexiona sobre el 
soporte digital sin transformar la tecnología como panacea para la educación pública. En la experiencia narrada, algunos estudiantes de grado lograron un aprendizaje participativo y colaborativo, basado en la ecología de saberes.

El último texto de este número es la reseña "Os bastidores da construção do dicionário 'Aurélio'", de Marcelo Módolo. Centrándose en el libro Por trás das palavras, de Cezar Motta, periodista nacido en Niteroi y egresado de la UFF, Modolo habla sobre el autor, sobre los apartados de la obra y hace un análisis preciso de su contenido, relacionando la temática del libro con el horizonte de retrospección y proyección de la historiografía de la lingüística;

Esta edición de la Revista Gragoatá permite ampliar las reflexiones sobre educación lingüística, decolonialidad y Epistemologías del Sur Global, la promoción del conocimiento de cuestiones relacionadas con los temas tratados, especialmente en Brasil, además de colaborar con reflexiones sobre el currículo y políticas públicas educativas.

Esperamos que este número contribuya a transformar el campo de la educación. Agradecemos a las autoras y autores que contribuyeron con su trabajo a dar forma a este tema por aceptar el desafío. Además, invitamos a los lectores a iniciar un diálogo sobre nuestras responsabilidades colectivas como educadores, investigadores, integrantes de la comunidad y de movimientos sociales por la descolonización de currículos, instituciones, saberes.

También esperamos que la lectura de los textos de este dossier también pueda recuperar una cierta pedagogía de la esperanza, como propone Paulo Freire (1992), sin la cual ningún cambio es posible.

\section{REFERENCIAS}

ALATAS, S. H. The Captive Mind and Creative Development. International Social Science Journal, v. 36, n. 4, 1974, p. 691-699.

ARROYO, M. O direito a tempos-espaços de um justo e digno viver. In: MOLL, J. (org.). Caminhos da Educação Integral no Brasil: direito a outros tempos e espaços educativos. Porto Alegre: Penso, 2012. p. 33-45. 
BAKHTIN, M. O problema do texto na linguística, na filologia e em outras ciências humanas. In: BAKHTIN, M. Estética da criação verbal. Tradução P. Bezerra. São Paulo: Martins Fontes, 2003c, p. 307-335.

CANDAU, V. M. F. Diferenças, educação intercultural e decolonialidade: insurgências. Revista Espaço do Currículo, v. 13, 2020, p. 678-686.

CARNEIRO, F. F. et al. Um grito contra o silêncio: o Dossiê ABRASCO na luta contra os agrotóxicos, pela ecologia de saberes e Agroecologia. Cadernos de Agroecologia, Anais do XI Congresso Brasileiro de Agroecologia, São Cristóvão, Sergipe, v. 15, n. 2, 2020.

FANON, F. Os Condenados da Terra. Trad. Enilce Albergaria Rocha e Lucy Magalhães. Juiz de Fora: Editora UFJF, 2005 [1952].

FANON, F. Pele Negra Máscaras Brancas. Trad. Renato da Silveira. Salvador: EDUFBA, 2008 [1961].

FAO; IFAD; UNICEF; WFP; WHO. The State of Food Security and Nutrition in the World 2020. Transforming food systems for affordable healthy diets. Roma: FAO, 2020.

FREIRE, P. Cartas à Guiné-Bissau: Registros de uma experiência em processo. 2. ${ }^{\text {a }}$ ed. Rio de Janeiro: Paz e Terra, 1978.

FREIRE, P.. Pedagogia do oprimido. 17a. ed. Rio de Janeiro: Paz e Terra, 1987.

FREIRE, P. Pedagogia da Esperança: um reencontro com a Pedagogia do Oprimido. Rio de Janeiro: Paz e Terra, 1992,

FREIRE, P.. Pedagogia da autonomia: saberes necessários à prática educativa. 25a. ed. São Paulo: Paz e Terra, 1996.

GANDHI, M. The Gandhi Reader. Bloomington: Indiana University Press, 1956.

GOMES, N.L. O movimento negro educador: Saberes construídos nas lutas por emancipação. Petrópolis: Vozes, 2017. 
LOOMBA, A, Colonialism/Postcolonialism. London: Routledge, 2002.

MARIMOUTOU, J.-C. C.; VERGÈS, F. Amarres: Créolisations india-océanes. Paris: L’Harmattan, 2005.

MEMMI, A. Retrato do colonizado precedido de Retrato do colonizador. Trad. Marcelo Jacques de Moraes. Rio de Janeiro: Civilização Brasileira, 2007 [1965].

MENESES, M. P. Justiça Cognitiva. In: CATTANI, A. et al (org.). Dicionário Internacional da Outra Economia. Coimbra: Almedina, 2009, p. 231-236.

MENESES, M. P. Os Sentidos da Descolonização: Uma análise a partir de Moçambique. OPSIS, v. 16, n. 1, 2016, p. 26-44.

MENESES, M. P. Colonialismo como Violência: a "missão civilizadora" de Portugal em Moçambique. Revista Crítica de Ciências Sociais, número especial de 2018, p. 115-140. Acesso em: 13 jul. 2021. Disponível em: https://journals.openedition. org/rccs/7741.

MIGNOLO, W. D. Colonialidade: o lado mais escuro da modernidade. Revista Brasileira de Ciências Sociais, v. 32, n. 94, jun. 2017, p. 1-18.

MUNDURUKU, D. O caráter educativo do Movimento Indígena Brasileiro (1970-1990). São Paulo: Paulinas, 2012.

NKRUMAH, K. Neo-colonialismo: Último estágio do imperialismo. Rio de Janeiro: Civilização Brasileira, 1967.

QUIJANO, A. Colonialidad del poder, eurocentrismo y América Latina. In: LANDER, E. (org.). La colonialidad del saber: eurocentrismo y ciencias sociales. Perspectivas latinoamericanas. Buenos Aires: CLACSO/UNESCO, 2000, p. 122-151.

SANTOS, B. S. Para uma sociologia das ausências e uma sociologia das emergências. Revista Crítica de Ciências Sociais, n. 63, 2002. Acesso em: 13 jul. 2021. Disponível em: http://journals. openedition.org/rccs/1285. 
SANTOS, B. S. Para além do Pensamento Abissal: Das linhas globais a uma ecologia de saberes. Revista Crítica de Ciências Sociais, n. 78, 2007. Acesso em: 13 jul. 2021. Disponível em: http://journals.openedition.org/rccs/753.

SANTOS, B. S. O fim do império cognitivo: a afirmação das epistemologias do Sul. Belo Horizonte: Autêntica Editora, 2019.

SILVA, T.T. O currículo como fetiche: A poética e a política do texto escolar. Belo Horizonte: Autêntica Editora, 2001.

SMITH, L. T. Decolonizing Methodologies. Research and indigenous peoples. London: Zed Books, 1999.

SUKARNO. Address given by Sukarno at the opening of the Bandung conference, 18 April 1955). In: Asia-Africa speak from Bandung. Djakarta: Ministry of Foreign Affairs, Republic of Indonesia, 1955, p. 19-29.

THIONG'O, N. Decolonizing the Mind. The struggle for cultural freedoms. London: James Currey, 1993.

TUCK, E.; YANG, K. W. Decolonization is Not a Metaphor. Decolonization: Indigeneity, Education \& Society, v. 1, n. 1, 2012, p. 1-40.

VOLÓCHINOV, V.N. Marxismo e Filosofia da Linguagem. Trad. de Sheila Grillo e Ekaterina Vólkova Américo. São Paulo: Ed. 34, 2017.

WALSH, C. Interculturalidad, Estado, Sociedad: luchas (de) coloniales de nuestra época. Quito: Ediciones Abya-Yala, 2009. 
Luciana Maria Almeida de Freitas es brasileña, Doctora en Letras Neolatinas (UFRJ) y Maestra en Lingüística (UERJ). Licenciada en Letras (Portugués-Español) y en Historia, siempre acerca en sus producciones el lengua(je) y la sociedad. Ha desarrollado investigaciones relacionadas con la educación lingüística y la formación del profesorado, articulando los campos de la lengua y la educación. Trabaja intensamente en defensa de la educación lingüística en otros idiomas, especialmente el español, en Brasil,

Maria Paula Meneses, mozambiqueña, obtuvo una maestría en historia de la Universidad de San Petersburgo (Rusia) y un doctorado en antropología de la Universidad de Rutgers (Estados Unidos). Inició su carrera académica en la Universidad Eduardo Mondlane (Maputo), en un diálogo no siempre fácil entre los tres proyectos 'mundiales' de educación. Se ha dedicado a investigar los contextos africanos postcoloniales y el papel de la historia oficial, la (s) memoria (s) y otras narrativas de pertenencia en los procesos identitarios contemporáneos. 